\title{
Kernos
}

Revue internationale et pluridisciplinaire de religion grecque antique

16 | 2003

Varia

\section{A. BUSINE, Les Sept Sages de la Grèce antique}

\section{Vinciane Pirenne-Delforge}

\section{(2) OpenEdition}

\section{Journals}

Édition électronique

URL : http://journals.openedition.org/kernos/846

DOI : $10.4000 /$ kernos.846

ISSN : 2034-7871

Éditeur

Centre international d'étude de la religion grecque antique

Édition imprimée

Date de publication : 1 janvier 2003

Pagination : 373-374

ISSN : 0776-3824

Référence électronique

Vinciane Pirenne-Delforge, «A. BusinE, Les Sept Sages de la Grèce antique », Kernos [En ligne], 16 | 2003, mis en ligne le 14 avril 2011, consulté le 23 septembre 2020. URL : http://

journals.openedition.org/kernos/846 ; DOI : https://doi.org/10.4000/kernos.846 
des origines de la tragédie et du drame satyrique, l'A. est toutefois conscient des enjeux et prend indirectement position dans un débat relancé encore tout récemment ${ }^{1}$. Les relations aux rituels ménadiques et à d'éventuels rituels initiatiques, et le contexte non négligeable des Grandes Dionysies (et l'arrière-plan du Dionysos d'Éleuthères) sont autant d'éléments que l'A. met en résonance avec les données dionysiaques du drame satyrique. L'ancrage rituel en est fortement souligné, mais c'est sur la fonction du drame satyrique après la trilogie tragique que se referme le livre : la distanciation «permet au spectateur de revenir au culte et à la fête dionysiaque et, réciproquement, de se libérer des émotions suscitées par la représentation tragique » (p. 403). Rire, cohésion et identité culturelle peuvent ainsi « naître du spectacle de la transgression ».

Vinciane Pirenne-Delforge (FNRS - Université de Liège)

Aude Busine, Les Sept Sages de la Grèce antique. Transmission et utilisation d'un patrimoine légendaire d'Hérodote à Plutarque, Université libre de Bruxelles, Centre de recherche sur la Cité grecque / Paris, De Boccard, 2002. 1 vol. $16 \times 24 \mathrm{~cm}, 144 \mathrm{p}$. (Culture et cité, 1). ISBN : 2-7018-0148-6.

La syllogè des Sept sages a traversé tout le monde antique, jusqu'à d'ultimes avatars médiévaux. La bibliographie sur le sujet, dont l'A. souligne à juste titre le caractère obsolète, trouve dans ce petit ouvrage un rajeunissement bienvenu, servi par une méthode historique rigoureuse. Trois parties articulent la réflexion autour de l'émergence de la syllogè, de son contenu et sa diffusion, et de son utilisation par Plutarque. Sept chapitres numérotés en continu traversent les trois parties qui fournissent chacune une conclusion intermédiaire particulièrement commode.

L'analyse des textes d'Hérodote et de Platon conduit l'A. à supposer que l'association des Sept sages vit le jour au $\mathrm{vi}^{\mathrm{e}}$ siècle, quand Delphes chercha à fédérer les «sagesses locales » pour la plus grande gloire de son Apollon et pour l'affirmation de son statut de centre de la culture grecque. Le contexte aristocratique et civique des enjeux de l'affaire est adéquatement souligné, tout comme la réappropriation athénienne du thème des Sept sages dans le contexte anti-tyrannique de la cité du ve siècle. C'est au départ de ce modèle athénien qu'une sorte d'universalisation de la légende se fera jour par la suite, et l'A. suit pas à pas, au rythme des sources disponibles - parfois désespérément lacunaires -, les moindres traces des Sept sages à la période hellénistique. C'est le plus gros chapitre du livre, qui interroge notamment avec beaucoup de pertinence le statut du texte de Diogène Laërce comme «source» privilégiée pour cette période puisque bon nombre de références hellénistiques sont tirées de sa « compilation ». S'éloignant du contexte culturel archaïque qui l'avait vue naître, la syllogè deviendra toujours davantage une sorte de produit standard de la paideia, témoin et objet tout à la fois de la transmission du savoir et de la culture grecs.

En comparaison des pauvres lambeaux d'information qui informent sur la période hellénistique, l'œuvre de Plutarque occupe une place privilégiée dans le traitement de la syllogè puisqu'il a consacré tout un traité au banquet des Sept sages et que le thème apparaît aussi dans la Vie de Solon et le traité sur l'Epsilon de Delphes. "[L']intérêt [de Plutarque] pour la sagesse des Sept sages peut se resituer dans un vaste programme de restauration de l'image défaillante du sanctuaire de Delphes (p. 111) ». Toutefois, Plutarque n'exploitera nulle part un des thèmes récurrents de la syllogè, à savoir la dédicace à l'Apollon pythien de l'objet, coupe ou trépied, qui était destiné «au plus sage des Grecs ». La seule mention de cette dédicace apparaît dans la Vie de Solon $(4,2-7)$, et s'adresse à l'Apollon de Thèbes. Il est difficile de rendre véritablement compte de ces deux points de vue qui semblent contradictoires.

Tout au long du livre, c'est le terme de "légende " qui est utilisé pour désigner l'ensemble mouvant que constitue la réunion de ces personnages aux sentences laconiques. Bien que l'A. ne se prononce pas explicitement sur' ce point, le mot s'adapte très bien au

1 S. Scuelron, "Nothing to do with Dionysus': Tragedy misconceived as ritual", CQ 52 (2002), p. 102-137. 
contenu de la syllogè, en une analogie intéressante avec les récits hagiographiques «à raconter ", legenda, ce qui le distingue adéquatement du «mythe ". Il est dès lors étonnant de voir apparaître le titre «Le mythe d'Arion » au chapitre VI, alors que le contexte d'énonciation du récit est identique. Mais le point est véniel... Ce parcours très bien mené et bien documenté se lit avec plaisir et permet de présager le meilleur pour la suite des travaux de cette jeune chercheuse.

Vinciane Pirenne-Delforge (FNRS - Université de Liège)

William D. Furley, Jan Maarten Bremer, Greek Hymns. I: The Texts in Translation. II: Greek Texts and Commentary, Tübingen, Mohr Siebeck, 2001. 2 vol. $15 \times 23 \mathrm{~cm}$, xxII +411 \& 443 p. (Studien und Texte zu Antike und Christentum, 10). ISBN : 3-16$147527-5$ \& 3-16-147553-4.

Par cette publication, l'intention des auteurs est de mettre à la disposition du public une sélection représentative des hymnes grecs (de l'âge classique - et même antérieur - à la période hellénistique), qui réunisse en une sorte de panorama aussi bien des textes issus des découvertes archéologiques ou papyrologiques des deux siècles écoulés, que des textes transmis par la tradition manuscrite «normale». Il s'agit donc d'une édition de quelque soixante-dix hymnes de provenances diverses.

L'ouvrage est conçu en deux volumes complémentaires, aptes à s'adresser éventuellement à des publics différents. En effet, le volume I se compose d'une introduction générale (pour dresser un bilan des connaissances concernant les hymnes grecs), suivie d'une traduction en vers et d'une notice plus ou moins développée sur chacun des hymnes choisis (son auteur, les circonstances de sa découverte, le genre auquel il appartient, ses qualités littéraires, etc.); ce tome est donc aisément accessible à tous ceux qui, sans être hellénistes, s'intéressent à l'histoire des religions, à l'anthropologie culturelle, à la théologie. Le volume II quant à lui s'adresse à une audience plus spécialisée : il offre le texte grec accompagné d'un apparat critique, et de tous les renseignements souhaitables concernant les éditions et études antérieures, l'analyse métrique, la datation probable; vient ensuite un commentaire serré vers par vers, aussi bien au plan de la langue qu'à celui du contenu. Cette présentation en deux volumes permet de lire commodément en regard le texte et sa traduction.

Les textes retenus pour cette sélection sont (dans chacun des deux volumes) répartis selon douze chapitres : les sept premiers classent les hymnes en fonction de la provenance géographique des sources épigraphiques et lyriques (Crète, Delphes, Délos, Lesbos et Ionie, Thèbes, Epidaure, Athènes); les quatre suivants examinent les sources théâtrales les chapitres huit, neuf et dix concernant respectivement chacun des trois tragiques (Eschyle : Suppl., Ag., Eum.; Sophocle : Ant., O.R., O.C.; Euripide : Hipp., Hclides, Ion, I.T.), le onzième Aristophane (Cav., Lysistr., Thesm., Gren.); enfin le douzième et dernier chapitre est consacré à cinq hymnes variés qui n'entraient pas dans les classifications précédentes. Si le volume I fait précéder les textes d'une introduction, le volume II les fait suivre d'appendices extrêmement précieux : sur les épithètes et attributs des dieux, sur les lieux sacrés (leurs noms et les termes servant à les décrire), sur l'accompagnement musical. Enfin chacun des deux tomes se clôt sur un index (un index général pour le premier; un index des noms et mots grecs judicieusement choisis pour le second), et chacun comporte une bibliographie. L'inconvénient de ces deux bibliographies est qu'elles se recoupent dans une assez large mesure. Mais l'avantage (qui prime amplement) est que chaque volume est autonome (à propos de la bibliographie du volume II, on peut observer que certains travaux mentionnés donnent l'impression de n'être pas toujours utilisés autant qu'ils auraient pu l'être : par ex. p. 29-30 de II, un mot sur le sens de $\lambda(\sigma \sigma o \mu a \iota$ n'aurait pas semblé superflu, et p. 116, en rester pour ápátav au LSS paraît un peu court; mais cette réserve ne concerne qu'un menu détail ponctuel). Pour l'un comme pour l'autre tome, on est sensible à l'étendue de l'information ainsi regroupée.

Les A, proposent donc dans cet ouvrage un large éventail d'anciens hymnes religieux qui nous restent de la Grèce, jusqu'à la période hellénistique. Ce qui fait le prix de cette publication est le rassemblement de témoignages jusqu'ici épars, ainsi que le parti de considérer sur le même plan textes épigraphiques et textes « littéraires ». Sans doute a-t-il 